\title{
Influence of Different Dosages of Selenium Yeast in the Diets of Laying Hens Cross Lohmann Brown on Metabolic Indices and Egg Productivity
}

\author{
Yuri Nikolayevich Prytkov, Anna Aleksandrovna Kistina \\ and Maxim Yurievich Chervyakov
}

\begin{abstract}
FSBEI HPE «Ogarev Mordovia State University», 68, Bolshevistskaya str., Saransk, 430005, Republic of Mordovia, Russia.
\end{abstract}

http://dx.doi.org/10.13005/bbra/2125

(Received: 15 March 2016; accepted: 27 April 2016)

\begin{abstract}
There was implemented the research on the study of the effect of different doses of selenium organic preparation Selenium Yeast on nutrient digestibility of the diet substances, morphological, biochemical parameters and mineral composition of blood, and egg productivity. According to the principle of analog pairs, there were formed 4 experimental groups, each of which received a certain dosage of the preparation with a daily ration. The research has given the results that addition of Selenium Yeast at a dose of $\mathbf{1 5 0}$ grams per ton of compound animal feedstuff of laying hens enhances digestibility of nutrients, normalizes homeostasis parameters, increases egg production and egg weight, and improves morphological parameters.
\end{abstract}

Key words: Selenium Yeast, egg production, egg weight, digestibility, hemoglobin, compound animal feedstuff, egg yolk, egg shell, eggshell thickness, selenium.

Providing the population of our country with high-quality foodstuffs has been and remains the most important economic task. In this regard, it becomes particularly relevant to increase the production of poultry as the main source of easily digestible and biologically proper food. The quality of food, especially of animal origin, is of paramount importance during the formation and preservation of human health, maintenance of the adaptive capabilities of his organism to the environment. The quality of such products is determined, in particular, by their trace element composition and to a large extent by the content of selenium. Russia produces little of such poultry products; that is why, poultry farms have gradually shifted to the

\footnotetext{
* To whom all correspondence should be addressed.
}

production of eggs enriched with trace elements and vitamins. With the appearance of organic forms of selenium, real prerequisites were created for solving the problem of selenium deficiency in the human diet by the consumption of eggs enriched with this element (Shtele, 1979: Tuchemsky, 1999).

The analysis of the published data shows that the range of compounds, which are potential suppliers of selenium in the body of farm animals and poultry, is rather narrow, and sodium selenite is the most widely used preparation. In the recent years, great importance was attached to the use of environmentally friendly, biologically active elements and products in the animal feeding, which have a positive impact on their biochemical, immunological, hematological and productive parameters. According to the published data, it was proved that the use of organoselenium preparations increases the growth of young animals and poultry productivity, and normalizes metabolism in the 
body. However, the data on the efficacy of the use of organoselenium preparation Selenium Yeast in feeding laying hens are small and rather contradictory. Many aspects of the organoselenium preparation Selenium Yeast impact on the body of poultry were not fully elucidated (Kistina, 2011; Prytkov et al., 2010; Kistina et al., 2013; Kistina, 2015).

In this regard, the research aimed at enriching hen eggs with selenium by introduction of Selenium Yeast into the diet of laying hens, and the study of the effect of different doses on metabolism and egg efficiency, are important.

\section{Methodology}

In order to achieve the set objectives, at the Veterinary Clinic of the Agronomy Institute was organized a scientific and economic experiment, and on its background, the physiological one for optimization of selenium in the diets of laying hens. Laying hens were selected according to the principle of analog pairs, and there were formed 4 groups of 30 animals each. The experiment lasted from 21 to 80 weeks of age.

Table 1. Research scheme

\begin{tabular}{lccl}
\hline Group & $\begin{array}{c}\text { Number of } \\
\text { animals }\end{array}$ & $\begin{array}{c}\text { Age at the } \\
\text { beginning of the } \\
\text { experiment, } \\
\text { weeks }\end{array}$ & Feeding habits \\
\hline Control & 30 & 21 & Basic diet (BD) \\
$1^{\text {st }}$ test & 30 & 21 & BD +100 g Selenium Yeast per ton of compound animal feedstuff \\
$2^{\text {nd }}$ test & 30 & 21 & BD +150 g Selenium Yeast per ton of compound animal feedstuff \\
$3^{\text {rd }}$ test & 30 & 21 & BD +200 g Selenium Yeast per ton of compound animal feedstuff \\
\hline
\end{tabular}

Feeding of the experimental poultry was total mixed compound animal feedstuff, in accordance with the standards recommended by VNITIP according to the recipe No. PK-1-1-3 (Kalashnikov et al., 2003). The temperature and light regime, air humidity, the front of feeding and watering of poultry during the experiment, corresponded to the standards recommended by VNITIP. Energy and nutrient content was the same in the poultry groups under experiment and differed only in the content of selenium.

Laying hens in the control group received their basic diet (BD) without organoselenium preparation. Laying hens in the experimental groups received different concentrations of selenium as part of Selenium Yeast according to the research scheme given in Table 1. Dosages of the seleniumcontaining preparations were introduced in the standard compound animal feedstuff by step-bystep mixing in the precision feeder.

Selenium in chicken eggs was determined by the atomic absorption spectrometer MGA-915 with a mercury hydride device RGP-915.

The digital material of the research was processed by the methods of variation statistics using the "Microsoft Office" software package on PC.

\section{RESULTS}

One of the important reserves of increasing the productivity of farm poultry is improving their nutrient intake used in the animal feed. The productivity of farm poultry is closely related to individual, clan and breed characteristics, feeding and maintenance conditions, and to a large extent does not only depend on the rations balance with basic organic nutrients, but on the trace elements performing a vital role in metabolism. In order to provide maximum growth of the poultry or to obtain the highest productivity, they must be provided with proper compound animal feedstuff containing all the necessary nutrients, minerals and biologically active substances. Selenium is one of such essential trace elements (Georgievsky et al., 1979).

N. G. Makartsev (1999) points out that insufficient feeding, in any respect, makes it improper, and has a significant impact on productivity and efficiency of feed use. In this regard, we have studied the effects of different dosages of organoselenium preparation Selenium Yeast in diets on nutrient digestibility by laying hens cross Lohmann Brown. 
As a result of our physiological experiment it was found that inclusion of different doses of Selenium Yeast in the diet of laying hens contributed to the increase in the digestibility of nutrients. Thus, using different levels of Selenium Yeast in the diets, digestibility of dry substance in laying hens from the $2^{\text {nd }}$ test group was larger than in the poultry from the control group by $6.0 \%$, of organic substance by $7.47 \%$, of crude protein by $7.0 \%(\mathrm{P}<0.01)$ and of crude fiber by $1.19 \%$.

In case of increasing the dosage of organoselenium preparation Selenium Yeast in the diet of laying hens to 200 grams per ton of compound animal feedstuff, the decrease in digestibility of nutrients respectively relative to the $2^{\text {nd }}$ test group was observed: dry substance by $1.05 \%$, organic substance by $0.51 \%$, crude protein by $0.51 \%$, crude fiber by $0.86 \%$, nitrogen-free extractive substances by $1.66 \%$. Together with this, the results have shown that nutrients digestibility in experimental groups is higher than in the control one: dry substance by $4.95 \%$, organic substance by $6.96 \%$, crude protein by $6.49 \%$, crude fiber by $0.33 \%$, nitrogen-free extractive substances by $4.34 \%$. Higher digestibility of nutrients in the poultry in the $2^{\text {nd }}$ test group is probably achieved both through stimulation of digestive enzymes in the gastrointestinal tract under the influence of optimal dosage of selenium and through the component structure in the composition of Selenium Yeast entering the body of poultry. In order to control the physiological state and progress of the biochemical processes in the body of the poultry under the influence of different concentrations of selenium, regulated by the organoselenium preparation Selenium Yeast, we have studied the dynamics of morphological and biochemical blood parameters of laying hens.

The analysis of the obtained data has shown that in the blood of laying hens in the $2^{\text {nd }}$ test group receiving Selenium Yeast in the amount of $150 \mathrm{~g}$ per ton of compound animal feedstuff, there was an increase in the content of erythrocytes and hemoglobin by $10.35 \%$ and $11.52 \%$, respectively, if compared to the parameters of the control group - by $2.19 \%$ and $1.96 \%$; by $1.23 \%$ and $1.36 \%$ - to the parameters of the $1^{\text {st }}$ and $3^{\text {rd }}$ test group. All this indicates a more intensive progress of redox processes in the body of the poultry.

The important indicator of protein metabolism is the protein content in the blood, its main factions and their ratio (Golikov et al., 1991). Addition of Selenium Yeast in different doses in the diet of the tested poultry has changed the content of total protein in the blood serum. During our studies, the hens from the $2^{\text {nd }}$ test group had the total protein level in blood by $4.41 \%$ higher than that from the control group and respectively by $0.25 \%$ and $0.86 \%$ higher than in the $1^{\text {st }}$ and $3^{\text {rd }}$ test group.

The changes were also observed in the content of albumins and globulins in the blood serum. As for the effect of Selenium Yeast dosages on the fractional composition of blood serum proteins, a positive effect on the concentration of albumins and globulins should be noted. The concentration of albumins and globulins in the laying hens from the $2^{\text {nd }}$ test group was by $8.02 \%$ and $6.35 \%$ higher than in the control group, and respectively by $1.03 \%$ and $2.38 \%$; by $0.60 \%$ and $2.23 \%$ higher than in the $1^{\text {st }}$ and $3^{\text {rd }}$ test group.

Addition of Selenium Yeast in the diets of laying hens had a certain impact on the mineral composition of the poultry blood. Thus, the content of calcium and phosphorus in the blood serum of laying hens from the $2^{\text {nd }}$ test group was higher by $3.87 \%$ and $4.06 \%$ compared to the analogues from the control groups and was higher by $1.72 \%$ to $1.59 \%$; and by $0.68 \%$ and $1.99 \%$, respectively, if compared to the results of the $1^{\text {st }}$ and $3^{\text {rd }}$ test group. The obtained results indicate that in order to maintain normal physiological processes, it is necessary for poultry to get with food an optimal concentration of selenium in Selenium Yeast. This is one of the factors determining the efficiency of feed use and increase in the productivity of laying hens.

Egg production is a complex quantitative indicator determined by the interaction of many genes. It depends on many internal and external factors. Egg production is positively influenced by the use of such factors as heredity, optimal environmental conditions: microclimate, feeding, rate of stocking, light regime and other; among the negative impacts are disorders in feeding and in living conditions, diseases and various stresses (Smetnev, 1978; Asriyan et al., 2005).

As a result of our studies, we have found that egg production of laying hens increases with age in all tested groups. The highest egg 
production was observed in the laying hens from the $2^{\text {nd }}$ test group, which is by $14.6 \%$ bigger if compared to the control group analogs. In order to determine the effect of the studied preparation on the dynamics of egg mass, they were weighted. With age, the egg mass increases. Thus, the average weight of the eggs of laying hens from the control group in the age of 22 weeks was $49.44 \mathrm{~g}$, 32 weeks: 59.2 g, 42 weeks: 63.4 g, which is respectively by $7.80 \% ; 7.2 \%$; $3.90 \%$ lower if compared to the analogs from the $2^{\text {nd }}$ test group. It should be noted that during the experiment a positive dynamics in the growth of the egg mass in the experimental poultry was revealed, but at the same time certain differences in the egg weight were established, associated with both age and dosage of Selenium Yeast in the diet. Feeding hens with a diet containing Selenium Yeast in the amount of $150 \mathrm{~g}$ per ton of compound animal feedstuff provided the increase in their egg mass in the age of 22 weeks by $6.7 \%$ and $7.8 \%$; 32 weeks: by $7.3 \%$ and $2.2 \%$; 42 weeks: by $3.9 \%$ and $2.6 \%$ respectively, compared to the control and the $3^{\text {rd }}$ test groups.

The shape of eggs in different breeds and certain laying hens is varied and determined by the genetic features, as well as the structure of the oviduct and the nature of its walls contraction during egg formation. Egg shape is generally evaluated according to the index by dividing the small diameter by the large one, and the result is given in percent. The optimum variation of the index is $70-78 \%$. Shape index is largely associated with the amount of egg breakage and cracked eggs. Thus, when laying hens are kept in cells, with the egg shape index of 73.0-76.0\% egg breakage and cracked eggs amount to $8.8 \%$; when the egg shape index is below $73.0 \%$ and above $78.0 \%$ egg breakage and cracked eggs vary from $15.0 \%$ to $21.0 \%$. Besides this, long or round eggs are nonstandard. Deviations from the normal shape do not only lead to deterioration of other quality parameters of eggs, but at the same time to difficulties in their sorting and packing (Alekseev et al., 2003).

Feeding poultry with selenium as part of Selenium Yeast had a marked effect on the receipt of the eggs with the optimal shape index (75.5-76.8\%).

Use of different dosages of organoselenium preparation promoted the increase in the egg shape index by $2.0 \%$ if compared to the control group.

Shell thickness defines its strength and varies from 200 to 600 microns. Shell strength is considered satisfactory at a thickness of 320 microns and more. Strong and solid eggs must have a shell thickness of 350 microns and more. When the thickness of the shell is of 310 micron, egg breakage and cracked eggs amount to $21.8 \%$; when it is of 360 microns: $6.8 \%$. Based on the objective data, the highest thickness of the shell egg among laying hens was found in the $2^{\text {nd }}$ test group - 345.9 microns, which is by 3.6 microns larger if compared to the control group.

Eggs solidity was higher in all the tested poultry if compared to the control group, by $0.003-$ $0.007 \mathrm{~g} / \mathrm{cm}^{3}$.

Accumulation of selenium in the eggs of farm poultry is important as an indicator that they have selenium, and it is the characteristics of nutritional value of the natural source of trace element for humans. Selenomethionine contained in eggs is digested better in the human body than other forms of selenium. This form of selenium has a strong anti-cancer effect. It reduces the risk of heart diseases, enhances immunity, removes heavy metals from the body and is involved in spermatogenesis.

The analysis of the published data shows that the specter of compounds which are potential suppliers of selenium in the body of farm animals and poultry is rather narrow. Nowadays we have the organic form of selenium in the Selenium Yeast preparation. Because of lower toxicity and prolonged action, organic form of selenium is more preferable to satisfy the needs of poultry in this trace substance. In this regard, our research is aimed at the study of the possibility to enrich hen eggs with selenium by feeding laying hens with different dosages of Selenium Yeast. In order to determine the concentration of selenium in the egg, from each experimental group we have taken 3 eggs. The amount of selenium was separately determined in the shell, egg white and yolk.

After the research we have found that inclusion of Selenium Yeast in the diet of laying hens at a dose of 100, 150 and $200 \mathrm{~g} / \mathrm{t}$ of compound animal feedstuff contributed to accumulation of selenium in the eggs. The highest concentration was found in the eggs of the laying hens from the 
$2^{\text {nd }}$ test group which had $300 \mathrm{mg}$ of selenium per 1 ton of compound animal feedstuff. Thus, the concentration of selenium in the eggs of laying hens from the control group at the beginning of the experiment amounts to $1.24 \mathrm{mcg} / \mathrm{egg}$, and at the end $-2.13 \mathrm{mcg} / \mathrm{egg}$; the $2^{\text {nd }}$ test group had 6.89 $\mathrm{mcg} / \mathrm{egg}$ and $15.69 \mathrm{mcg} / \mathrm{egg}$ respectively, which is 5.5 and 7.4 times higher if compared to the analogs from the control group.

Thus, the obtained data make it possible to state that feeding the laying hens cross Lohmann Brown with organoselenium preparation at a dose of 200, 300, $400 \mathrm{~g}$ per 1 ton of compound animal feedstuff contributes to the enrichment of eggs with selenium from 5.08 to $15.69 \mathrm{mcg} / \mathrm{egg}$.

\section{DISCUSSION}

The focus area in poultry industry becomes the substitution of many trace elements in inorganic form, used for a long time, by organic analogues, which are more effective and biologically available; among them selenium occupies an important place. Numerous studies have shown that organic selenium improves production performance, strengthens the immune system, increases the antioxidant status, and eggs become enriched with trace elements. A person, consuming eggs enriched with selenium, prevents cancer of the gastrointestinal tract, cardiovascular diseases and a number of other diseases.

Organoselenium preparations provide the poultry body with normal metabolism, serving as biological catalysts, become part of different enzyme systems and hormones, are necessary for normal digestion of essential nutrients, thus having a beneficial effect on health and increasing egg production.

In the scientific and economic experiment we used Selenium Yeast in the diets of laying hens in order to enrich eggs with selenium. The diets of experimental groups contained equal amount of nutrients. The main difference in diets was the concentration of selenium.

Addition of Selenium Yeast in the diets of laying hens contributed to the increase in digestibility of nutrients. Digestibility of dry substance in laying hens from the $2^{\text {nd }}$ test group was higher than that of the poultry from the control group by $6.0 \%$, organic substance: by $7.47 \%$, crude protein: by $7.0 \%(\mathrm{P}<0.01)$, crude fiber: by $1.19 \%$. With the increase in the dosage of organoselenium preparation Selenium Yeast in the diet of laying hens up to $200 \mathrm{~g}$ per ton of compound animal feedstuff, there was observed a tendency of digestibility decrease of nutrients in respective relation to the $2^{\text {nd }}$ test group: dry substance by $1.05 \%$, organic substance: by $0.51 \%$, crude protein: by $0.51 \%$, crude fiber: by $0.86 \%$, nitrogen-free extractive substances: by $1.66 \%$. Perhaps, higher digestibility of nutrients in the experimental poultry from the $2^{\text {nd }}$ test group is achieved both through stimulation of digestive enzymes in the gastrointestinal tract under the influence of optimal selenium dosage and through the component structure as part of Selenium Yeast, entering the body of poultry. The obtained data are consistent with the data of A.A. Kistina, Yu.N. Prytkov, V.E. Kuleshov (2010).

Hematological parameters characterize the state of health, intensity and direction of metabolism and poultry productivity. Our studies of hematologic, biochemical parameters, and blood mineral composition, show the positive effect of optimal and increased dosage of organoselenium preparation Selenium Yeast on the body of experimental poultry. Our hematological data of the research are consistent with the work of A.A. Kistina, Yu.N. Prytkov, L.S. Tsarenkov (2015).

Feeding with different dosages of Selenium Yeast improves egg production and egg weight. The highest egg production was observed in the laying hens from the $2^{\text {nd }}$ test group, which is by $14.6 \%$ higher if compared to the analogs from the control group. Feeding of laying hens according to the diet containing Selenium Yeast in the amount of $150 \mathrm{~g}$ per ton of compound animal feedstuff provided the increase in their egg mass at the age of 22 weeks and by $7.8 \%$ and $6.7 \% ; 32$ weeks: $7.3 \%$ and $2.2 \%$; 42 weeks: by $3.9 \%$ and $2.6 \%$ respectively compared to the control and the $3^{\text {rd }}$ test groups.

Inclusion of organoselenium preparation in the composition of compound animal feedstuff improves the morphological parameters of eggs, had a marked effect on the receipt of the eggs with the optimal shape index (75.5 76.8\%) and contributed to the increase in the egg shape index by $2.0 \%$ if compared to the control group. The highest thickness of the egg shell in laying hens 
was found in the $2^{\text {nd }}$ test group amounting to 345.9 micron, which is by 3.6 micron bigger if compared to the control group. The obtained results agree with the data of S.I. Kizhapkin (2011).

Feeding with Selenium Yeast contributed to selenium accumulation in eggs, which is important as an indicator that they have selenium, and it is the characteristics of nutritional value of the natural source of trace element for humans. Selenomethionine contained in eggs is digested better in the human body than other forms of selenium. This form of selenium has a strong anticancer effect. It reduces the risk of heart diseases, enhances immunity, removes heavy metals from the body and is involved in spermatogenesis.

Inclusion of Selenium Yeast in the diets of laying hens in the dosage of 100, 150 and $200 \mathrm{~g} /$ t of compound animal feedstuff has contributed to eggs enrichment with selenium. The highest concentration was found in the eggs of laying hens from the $2^{\text {nd }}$ test group. Thus, the concentration of selenium in the eggs of laying hens from the control group at the beginning of the experiment amounts to $1.24 \mathrm{mcg} / \mathrm{egg}$, and at the end $-2.13 \mathrm{mcg} / \mathrm{egg}$; the $2^{\text {nd }}$ test group had $6.89 \mathrm{mcg} / \mathrm{egg}$ and $15.69 \mathrm{mcg} /$ egg respectively, which is 5.5 and 7.4 times higher if compared to the analogs from the control group.

Summarizing the results of our research, we can draw the following conclusion: apparently, the positive effect of the organoselenium preparation Selenium Yeast on the metabolic and productive performance of laying hens, is largely determined by the content of biologically active substances increasing metabolism and activating enzyme systems and hormones, which is accompanied by the improvement of quantitative and qualitative indicators of egg production.

\section{Opinion}

Thus, the use of organoselenium preparation Selenium Yeast at the rate of $150 \mathrm{~g} / \mathrm{kg}$ of compound animal feedstuff stimulates metabolism and has a positive impact on the overall clinical status of animals, stabilizes mineral metabolism in the body and increases egg production.

\section{CONCLUSIONS}

1. Feeding laying hens with organoselenium preparation Selenium Yeast in an amount of
150 g per ton of compound animal feedstuff contributed to the increase in digestibility of nutrients and use of minerals present in the diet.

2. The optimum dosage of selenium as part of Selenium Yeast, increases metabolism in the body, as evidenced by a big content of red cells, hemoglobin, total protein and its fractions in the blood.

3. Addition of organoselenium preparation Selenium Yeast in an amount of $150 \mathrm{~g}$ per ton of compound animal feedstuff contributed to the increase of egg production by $14.5 \%$, egg weight by $2.5 \mathrm{~g}$, improvement of morphological parameters and egg quality.

4. Inclusion of selenium in the diet of laying hens in the amount of 100, 150 and $200 \mathrm{mg}$ per ton of compound animal feedstuff contributed to eggs enrichment with selenium in the $1^{\text {st }}$ test group from 5.08 to 12 mcg/egg; $2^{\text {nd }}$ group: from 6.89 to $15.69 ; 3^{\text {rd }}$ group: from 5.38 to $13.81 \mathrm{mcg} / \mathrm{egg}$.

\section{REFERENCES}

1. Smetnev, S.I., Aviculture. Moscow: Kolos, 1978.

2. Georgievsky, V.I., B.N. Annenkov and V.T. Samokhin, Mineral Animal Nutrition. Moscow: Kolos, 1979.

3. Shtele, A.L., Improvement in Quality of Aviculture Products. Moscow: Rosselkhozizdat, 1979.

4. Alekseev, F.F., M.A. Asriyan and N.B. Belchenko, Industrial Aviculture. Moscow: Agropromizdat, 1991.

5. Golikov, A.N., N.U. Bazanov, Z.K. Kozhebekov et al., Physiology of Farm Animals. Moscow: Agropromizdat,1991.

6. Makartsev, N.G., Farm Animal Nutrition. Kaluga: SUE “Oblizdat”, 1999.

7. Tuchemsky, Technology for Growing HighLaying Broiler Chicken. Sergiev Posad, 1999.

8. Kochiah, I.I., M.G. Petrash and S.B. Smirnov, Aviculture. Moscow: KolosS, 2003.

9. Bessarabov, B.F., E.I. Bondarev and T.A. Stolyar, Aviculture and Technology for Production of Eggs and Poultry. Saint Petersburg: “Lan” Publishing House, 2005.

10. Kochiah, I.I., M.G. Petrash and S.B. Smirnov, Aviculture. Moscow: KolosS, 2003.

11. Kalashnikov, A.P., V.I. Fisinin, V.V. Shcheglov et al., Standards and Feeding Rations for Farm 
Animals. Reference book (3rd ed., updated and revised). Moscow, 2003.

12. Prytkov, Yu.N., A.A. Kistina, V.E. Kuleshov et al., Effect of Sel-Plex Preparation on Metabolism and Productivity of Vrossbred Black-Motley x Limousin Bull-Calves. Agricultural Science of Euro Northeast, 2010; 4: 32-37.

13. Kizhapkin, S.I., Influence of Organo-Element Compound "Krezooferan" on Metabolism and Productivity of Laying Hens Rearing Flocks, Ph.D. Thesis Abstract, Saransk, 2011.

14. Kistina, A.A., Scientific and Practical Substantiation of Application of SeleniumContaining Preparations in Feeding of Cattle, Ph.D. Thesis Abstract, Saransk, 2011.

15. Kistina, A.A., Yu.N. Prytkov and V.E. Kuleshov, Influence of Organoselenium Preparation "SelPlex” on Nutrients Digestibility in Calves Diet.
In Resource-Saving Environmentally Friendly Technologies for Production and Processing of Agricultural Products (Proceedings of the $9^{\text {th }}$ International Scientific and Practical Conference), Saransk: Mordovia University Publishing House, 2013; 118-120.

16. Prytkov, Yu.N., A.A. Kistina and L.S. Tsarenkova, Use of Selenium-Carotene Supplement in Aviculture. In Intensive Production Technology of Livestock Productions. Proceedings of the International Scientific and Practical Conference, Penza, 2015; 84-87.

17. Kistina, A.A., Use of Selenium-Carotene Supplement in the Diets of Laying Hens. In Scientific Bases of Modern Agricultural Technologies in Agricultural Production (Proceedings of the All-Russian Scientific and Practical Conference), Saransk, 2015; 284-288. 